\title{
Article
}

\section{Are Comic Books an Effective Way to Engage Nonmajors in Learning and Appreciating Science? ${ }^{1}$}

\author{
Jay Hosler* and K. B. Boomer ${ }^{\dagger}$ \\ ${ }^{*}$ Department of Biology, Juniata College, Huntingdon, PA 16652; ${ }^{\dagger}$ Department of Mathematics, \\ Bucknell University, Lewisburg, PA 17837
}

Submitted July 15, 2010; Revised June 11, 2011; Accepted June 14, 2011

Monitoring Editor: Karen Kalumuck

\begin{abstract}
Comic books employ a complex interplay of text and images that gives them the potential to effectively convey concepts and motivate student engagement. This makes comics an appealing option for educators trying to improve science literacy about pressing societal issues involving science and technology. Here, we report results from the first systematic assessment of how a science comic book can affect student learning and attitudes about biology. We used pre- and postinstruction instruments to measure students' attitudes about biology, attitudes about comics, and content knowledge about evolution before and after using the science comic book Optical Allusions in their classes. On the preinstruction instrument, nonmajors reported the lowest scores on the content test and attitude surveys relative to the other groups. However, on the postinstruction instrument, nonmajors' content scores and attitudes showed a statistically significant improvement after using the comic book, particularly among those with lower content knowledge at the start of the semester. The improvement in attitudes about biology was correlated to attitudes about comics, suggesting that the comic may have played a role in engaging and shaping student attitudes in a positive way.
\end{abstract}

\section{INTRODUCTION}

According to the National Assessment of Education Progress, the science proficiency of high school seniors dropped from $21 \%$ in 1996 to $18 \%$ in 2000 and remained at $18 \%$ in 2005 (Grigg et al., 2006). As a result, the public's science literacy

DOI: $10.1187 /$ cbe.10-07-0090

Address correspondence to: Jay Hosler (hosler@juniata.edu).

${ }^{1}$ This paper assesses a commercially available science comic book entitled Optical Allusions that was written and drawn by the corresponding author, Jay Hosler. The work reported here uses this book to test the effectiveness of comics as a means of conveying content, engaging nonmajors, and improving attitudes about science. This is in no way to be construed as a promotion of this book, especially to the exclusion of others. In fact, our results support the idea that comics, in general, can be an effective pedagogical tool. To that end, Hosler maintains the following free website to promote the use of a wide range of comics by different authors for different disciplines: http://comicbooksyllabus.com.

(c) 2011 J. Hosler and K. B. Boomer. CBE-Life Sciences Education (C) 2011 The American Society for Cell Biology. This article is distributed by The American Society for Cell Biology under license from the author(s). It is available to the public under an AttributionNoncommercial-Share Alike 3.0 Unported Creative Commons License (http:/ / creativecommons.org/licenses/by-nc-sa/3.0).

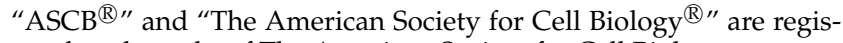
tered trademarks of The American Society for Cell Biology. is remarkably low. Only one in five Americans comprehends or appreciates the value or process of scientific inquiry (National Science Board [NSB], 2000). To combat this, the NSB on Communicating Science and Technology to the Public has underscored the need to communicate the fascination, joy, and utility of science (NSB, 2000). Traditional textbooks do not always make this possible, especially if students are already uncomfortable with the material. According to the NSB's Science and Engineering Indicators for 2004, textbooks now contain more content that is presented with less coherence (NSB, 2004). In this paper, we report data that suggest comic book stories can play a significant role in conveying content in a coherent manner and, in the process, improve the attitudes that non-science majors have toward biology.

The potential value of comics in education and student literacy is not a new concept. Educators have been using comics in the classroom for over 60 years. Instructors who incorporate comics into their curricula suggest that comics generate increased individual student interest (Sones, 1944) and, according to at least one teacher, make "learning too easy" (Hutchinson, 1949). Comics have been used to motivate children to read (Haugaard, 1973), train students in the language arts (Williams, 1995), teach collegiate physics (Kakalios, 2002), outline business ethics (Gerde and Foster, 2008), and explain the maintenance of military equipment (Eisner, 1944). Comics are also being used in medical education and patient care 
(Green and Myers, 2010). The Maryland State Department of Education (MSDE) even started the Maryland Comic Book Initiative in which it piloted the use of comics such as Jim Ottaviani's Dignifying Science (biographical comic stories about women scientists) in middle school classrooms (MSDE, 2004; Ottaviani, 2009).

Few science educators could dispute the explanatory power of images and figures in traditional textbooks. The complex interplay of words and images in comics has the potential to go beyond the traditional textbook by weaving text and images into a story that can help generate coherence and context for the information. A pedagogical tool that engages students, motivates them to read, helps them remember content, and makes the whole process fun would be quite useful in the science curriculum. It is not surprising then that comics have found their way into some science classrooms. The literature concerning science education and science comics has recently been reviewed by Tatalovic (2009), and although there have been a number of articles published that suggest comics can be used in the classroom to motivate students, these arguments usually rely on anecdotal evidence for support and do not assess what role, if any, comics play in student success.

In this paper, we report the results from a comparative study to assess the pedagogical effectiveness of a comic book textbook called Optical Allusions. We focus on the role comics might play in engaging non-science majors. Relative to science majors, nonmajors are less motivated and interested in science and spend less time studying it (Knight and Smith, 2010). We hypothesized that using a comic book story to deliver scientific information would provide imagery and context that would enhance student learning and attitudes about biology.

\section{MATERIALS AND METHODS}

\section{The Comic Book Textbook}

Optical Allusions is a comic book textbook written by one of us (J.H.) that uses biological themes about vision and evolution as scaffolding for the comic book story. The comic book was designed for a nonmajors Sensory Biology course and was used during the section of the course that focuses on vision and evolution. The main character in Optical Allusions is Wrinkles the Wonder Brain, a lab technician for the Graeae Sisters from the Perseus legend. Wrinkles' primary responsibility is to shuttle the sisters' single eye among them as they need it. When he trips and drops the eye into a vat of distilled imagination, he goes in after it and proceeds to have eight six- to eight-page eye-themed adventures. During his search, he is introduced to concepts such as evolution and natural selection, eye anatomy, sexual selection, evolutionary development of the eye, color vision, phototransduction, and systematics (Figure 1). Each of the comic stories is written with a cliffhanger to draw readers into the next chapter and beyond the required reading.

Interleaved with the comic stories are fully illustrated, traditional text pieces that provide students and instructors with a more in-depth exploration of the biology introduced in the immediately preceding comic story. Each chapter includes study questions that are designed to help students make connections between the content and story as well as connections

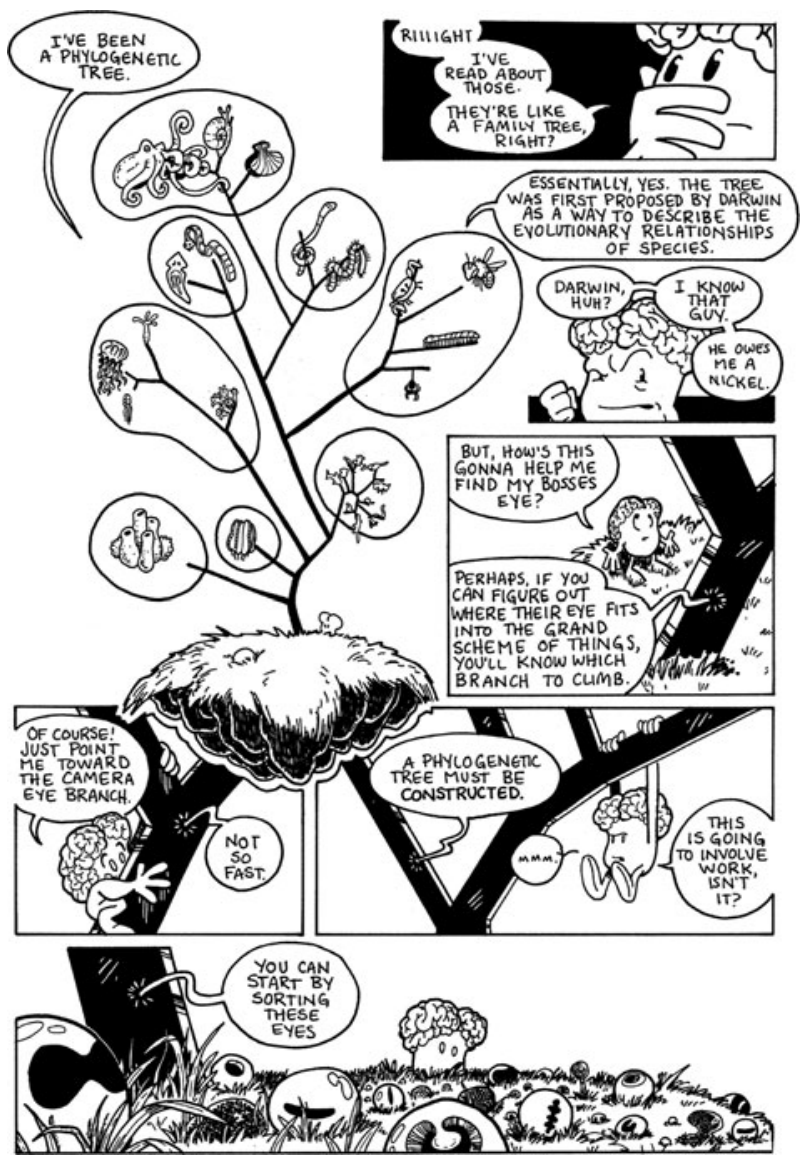

Figure 1. A page from Optical Allusions in which the protagonist, Wrinkles the Wonder Brain, meets a phylogenetic tree named Yggdrasil and is instructed on basic phylogenetic concepts. The concepts introduced in the comic story are expanded upon in the text piece that interleaves the comic book chapters.

among content in other chapters of the book. Both the comic stories and traditional text are fully indexed, and there is a complete bibliography of primary and secondary literature for further reading.

\section{Demographics}

This study was conducted using four biology courses taught by one of us (J.H.) at Juniata College during the Spring 2009 semester. Juniata College is a small liberal arts college located in a rural setting in central Pennsylvania. The student body is $57 \%$ female, $7 \%$ international, and $7 \%$ domestic minority. Thirty percent of the students are the first generation in their family to attend college. Departments at Juniata College are organized into three major divisions: natural sciences, social sciences, and humanities. The four courses that were part of the study had different demographics (Figure 2).

Sensory Biology (BI 142). Sensory Biology, a 100-level course designed for nonmajors, enrolled 24 students in 2009 (11 women, two domestic minorities, three international). Fifteen of the students had majors in the social sciences (communication, psychology, business, and education), three had majors in the natural sciences (environmental science, wildlife 

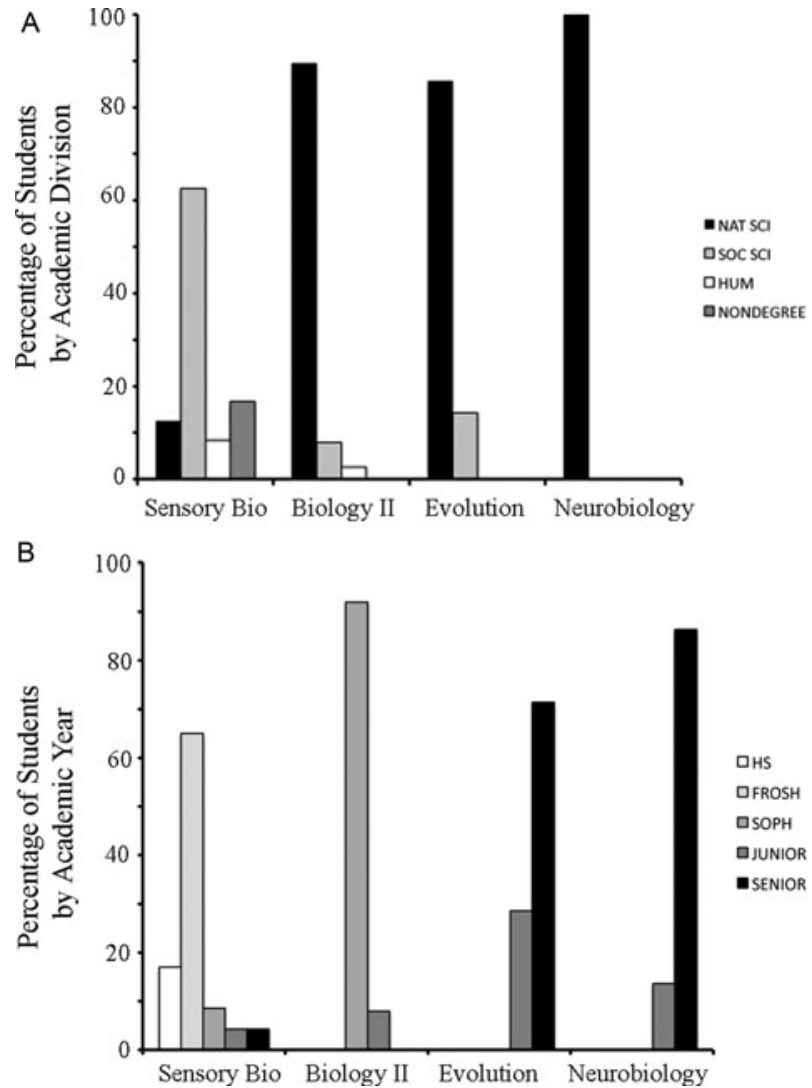

Figure 2. Demographics of the courses Sensory Biology (BI 142), Biology II (BI 106), Evolution (BI 339), and Neurobiology (BI 450). (A) Percentage of students with majors in a given academic division for each course. Juniata College categorizes departments into three major divisions: natural sciences, social sciences, and humanities. Nondegree refers to high school students taking the course for college credit. (B) Percentage of students from each class that are high school students, first years, sophomores, juniors, or seniors. Sensory Biology was composed primarily of first-year students from the social sciences. The other three courses were predominantly populated by upper-class students in the natural sciences.

conservation, and biology), two had majors in the humanities (French, studio art), and four were non-degree-seeking high school students. Students included high school seniors as well as freshmen through senior college students, with the typical student being in their first year of college.

Biology II (BI 106). Biology II, the second course in the introductory biology sequence, enrolled 38 students in 2009 (22 women, one international). Of the 38 students, 35 were sophomores and three were juniors. Of the students in Biology II, 34 had majors in the natural sciences (primarily biology with a few students in chemistry, geology, environmental science, and wildlife conservation), three were in the social sciences (anthropology, psychology, and education), and one was in the humanities (fine arts).

Organic Evolution (BI 339). Organic Evolution, an upperlevel elective course, enrolled 14 students in 2009 (10 women). The course was composed of juniors and seniors. Twelve had majors in the natural sciences (all biology), and two had majors in social sciences (anthropology and education). There were no nondegree, international, domestic minority, or humanities students in this class.

Neurobiology (BI 450). Neurobiology, an upper-level elective composed primarily of juniors and seniors, enrolled 22 students in 2009 (17 women, one domestic minority, and one international). All 22 of the students were biology majors.

Optical Allusions was used in Sensory Biology, Organic Evolution, and Neurobiology. These latter two courses have as a prerequisite BI-207, Dynamics of Biological Processes; the third course in the introductory biology sequence. Biology II (BI 106) was used as a comparison group. In this class, the same topics about the eye and evolution were covered, but Optical Allusions was not used. Instead, students in Biology II used Scott Freeman's Biological Science as a text.

\section{Summary of Pedagogical Approaches for Each Course}

The teaching approach in all four of the classes in this study was very similar. During lectures, J.H. worked primarily at the board, drawing and writing notes. Lectures were punctuated by frequent "quick questions and problems" that involve students working with the person beside them to figure out problems, how to interpret a graph, or design experiments. Student comments and solutions were used to generate class discussion of the material. For each class using Optical Allusions, students were assigned specific passages to read and the class discussed the story and the science from the reading during class, using the ridiculous situations of the comic book stories to put the concepts in context. The only major difference between approaches was that, in the introductory courses (Sensory Biology and Biology II), daily five-point quizzes were given, whereas in Neurobiology, quizzes were once a week; in Evolution, there were no quizzes at all.

Optical Allusions was the only text used in Sensory Biology when covering the topic of evolution and the eye. In the other courses, additional texts were used: Freeman's Biological Science in Biology II, Futuyma's Evolution in Organic Evolution, and Nicholls et al.'s From Neuron to Brain in Neurobiology. Although texts other than Optical Allusions were used in Organic Evolution and Neurobiology, Optical Allusions was used at the beginning of the semester in each class to introduce the topics to students. In Neurobiology, the topic of the eye was not revisited until the end of the semester so that the use of the text From Neuron to Brain between the time we finished with Optical Allusions and the postinstruction assessment instrument (see below) would have had minimal to no impact on student understanding of the content being assessed. Similarly, in Organic Evolution, the time between using Optical Allusions and the postinstruction assessment instrument was dedicated to a historical overview of evolutionary thought, content that does not overlap with that covered in the comic. In Biology II, the text was the sole source of content delivery.

The use of the comic and textbook in lecture used the same approach in all classes. Students were assigned readings from the text or comic, and the concepts were discussed in class.

\section{Assessment}

The students completed identical pre- and postinstruction assessment instruments; the preinstruction instruments were 
Table 1. Instrument reliability as assessed with Cronbach's alpha

\begin{tabular}{|c|c|c|c|c|c|}
\hline \multirow[b]{2}{*}{ Course } & \multirow[b]{2}{*}{ Time point } & \multicolumn{2}{|c|}{ Biology Attitude Scale } & \multicolumn{2}{|c|}{ Comic Attitude Scale } \\
\hline & & Part A & Part B & Part A & Part B \\
\hline \multirow[t]{2}{*}{ Sensory } & Post & 0.948 & 0.779 & 0.948 & 0.897 \\
\hline & Pre & 0.946 & 0.732 & 0.950 & 0.864 \\
\hline \multirow[t]{2}{*}{ Neurology } & Post & 0.839 & 0.820 & 0.968 & 0.791 \\
\hline & Pre & 0.866 & 0.744 & 0.892 & 0.828 \\
\hline \multirow[t]{2}{*}{ Evolution } & Post & 0.826 & 0.735 & 0.973 & 0.883 \\
\hline & Pre & 0.853 & 0.752 & 0.983 & 0.890 \\
\hline \multirow[t]{2}{*}{ Control } & Post & 0.929 & 0.758 & 0.934 & 0.893 \\
\hline & Pre & 0.946 & 0.735 & 0.948 & 0.795 \\
\hline \multirow{2}{*}{ Overall $^{\mathrm{a}}$} & Post & 0.933 & 0.770 & 0.952 & 0.878 \\
\hline & Pre & 0.950 & 0.746 & 0.952 & 0.837 \\
\hline
\end{tabular}

${ }^{\mathrm{a}}$ Overall includes responses from each of the four courses.

administered at the start of the semester, and the postinstruction instruments were administered $2 \mathrm{wk}$ after the completion of the unit on eyes and evolution. At both time points, the Biology Attitude Scale, the Comics Attitude Scale, and the same content-based assessment tool were used.

The Biology Attitude Scale (BAS; Russell and Hollander, 1975) was used to assess a change in attitude over time as opposed to measuring absolute attitude toward biology. The reliability of this BAS was validated by Rogers and Ford (1997). Russell and Hollander suggest that their scale could be used to measure a change in attitude in other subjects by changing the word "biology" for another subject matter area. Thus, we used a similar scale, which we termed the Comic Attitude Scale (CAS), by using the word "comic" in place of "biology" in the original BAS.

The attitude scales have two sections. The first ("Part A") consists of 14 Likert items on a 5-point scale. The second section ("Part B") consists of eight bipolar adjectives in a semantic differential scale; the same adjectives from the original scale were used on both the BAS and the CAS. The results were scored so that a strong, positive response toward biology/comics scored a 5, and a strong negative response was scored a 1 . Thus, the minimum and maximum scores on the attitude scales were 22 and 110; the minimum and maximum scores were 14 and 70 for Part A and 8 and 40 for Part B of each scale.

There was a high degree of internal reliability with these instruments in our study, as assessed with Cronbach's alpha (Table 1). The Cronbach alpha values for Part A of the BAS ranged from 0.826 to 0.949 ; for Part A of the CAS, the alpha values ranged from 0.892 to 0.973 . The lowest reliability was seen within the BAS semantic differential scale (Part B), ranging from 0.732 to 0.820 . The Cronbach alpha values for Part B of the CAS ranged from 0.791 to 0.897 . When initially developing the BAS, Russell and Hollander (1975) selected items so that the overall alpha value was at least 0.80 . In initial pretests, the alpha values for the Likert items (Part A) were 0.9 and for the semantic differential scale were 0.80 . Rogers and Ford (1997) reported a Cronbach alpha value of 0.95 for the Likert items. Thus, our measures of internal reliability are consistent with those reported elsewhere in the literature.

In addition, a content-based assessment instrument was also used pre- and postinstruction. This content knowledge instrument consisted of 23 multiple-choice questions. The score represents the number of questions correctly answered. The same content knowledge instrument was used in the four courses. The 23 content questions ranged from straightforward factual questions to questions requiring conceptual integration about topics such as natural selection and eye physiology. These questions were drawn from two primary sources: 1) prior test questions generated over the last 10 years by J.H. for his Sensory Biology, Neurobiology, and Organic Evolution courses; and 2) questions on the eye and evolution from the test bank for Scott Freeman's general biology textbook Biological Science. Optical Allusions was tested in two upper-level biology courses (Neurobiology and Organic Evolution) with students who had previously been exposed to some of the material on the content assessment. It is reasonable to assume that these upper-level students may have higher scores on the pretest content assessment than the students in Sensory Biology, who did not have similar prior exposure. Students in Biology II (BI 106, Functions of Cells and Organisms) might also have been expected to score higher on the pretest than Sensory Biology students, given that they may have been exposed to some, but not all, of the concepts in Biology I (BI 105), the required first course in the introductory biology sequence.

\section{RESULTS}

\section{Statistical Analysis}

The main objective of this analysis is to assess whether there is a significant increase in the average knowledge gained and positive attitudes toward biology and comics at the end of the course. The data were analyzed in two ways. First, an analysis was conducted using data from within each course, using a Wilcoxon sign rank sum (matched pairs) test. ${ }^{2}$ The null hypothesis is that the median change is equal to zero;

\footnotetext{
${ }^{2}$ The Wilcoxon sign rank sum (matched-pairs) test is the nonparametric equivalent to the matched-pairs $t$-test. The nonparametric test does not require the assumption of normally distributed populations and was used here due to the small sample sizes. In this study, significant Wilcoxon test statistics correspond to significant matched-pairs $t$-test results.
} 
Table 2. Summary of Wilcoxon matched pairs test for increase in median score

\begin{tabular}{|c|c|c|c|c|c|}
\hline Instrument & & Sensory Biology & Organic Evolution & Neurobiology & Biology II (control) \\
\hline \multirow{2}{*}{\multicolumn{2}{|c|}{ Content Knowledge }} & $5.0(4.0)$ & $4.0(6.0)$ & $3.0(3.5)$ & $3.0(4.0)$ \\
\hline & & $p<0.0001$ & $p=0.0313$ & $p=0.0001$ & $p<0.0001$ \\
\hline \multirow{6}{*}{ BAS } & Overall & $5.5(19.00)$ & $2.0(2.0)$ & $1.5(6.50)$ & $1.5(5.0)$ \\
\hline & & $p=0.0128$ & $p=0.0039$ & $p=0.1144$ & $p=0.1915$ \\
\hline & Part A & $6.0(15.0)$ & $2.0(5.0)$ & $0.0(4.0)$ & $1.0(5.0)$ \\
\hline & & $p=0.0104$ & $p=0.0313$ & $p=0.1965$ & $p=0.2509$ \\
\hline & Part B & $1.5(5.0)$ & $0.0(3.0)$ & $1.0(4.0)$ & $0.0(3.5)$ \\
\hline & & $p=0.1663$ & $p=0.5219$ & $p=0.2818$ & $p=0.3992$ \\
\hline \multirow[t]{6}{*}{ CAS } & Overall & $6.0(8.0)$ & $3.0(4.0)$ & $-0.5(9.0)$ & $-1.0(12.5)$ \\
\hline & & $p=0.0006$ & $p=0.0977$ & $p=0.3644$ & $p=0.4953$ \\
\hline & Part A & $4.0(7.0)$ & $1.0(3.0)$ & $1.0(6.5)$ & $-0.5(9.0)$ \\
\hline & & $p=0.0031$ & $p=0.1350$ & $p=0.4823$ & $p=0.2672$ \\
\hline & Part B & $2.0(2.0)$ & $0.0(3.0)$ & $-1.0(3.0)$ & $0.0(4.5)$ \\
\hline & & $p=0.0006$ & $p=0.1133$ & $p=0.0770$ & $p=0.2681$ \\
\hline
\end{tabular}

Cell key: Median (interquartile range)

Wilcoxon $p$ value

the one-sided alternative is that the median change score is greater than zero. Results are summarized in Table 2. Second, one-way analysis of variance (ANOVA) was used to assess whether the mean change score was the same for each course (see Table 3). In the presence of a significant overall F test, a Dunnett's post hoc test compared the treatment group means with the Biology II comparison group that did not use the comic book text. Residuals analyses were conducted (but are not reported here), verifying that assumptions have been met.

As outlined above, Optical Allusion was tested in three courses with the following sample sizes: Sensory Biology $(n=18)$, Organic Evolution $(n=9)$, and Neurobiology $(n=20)$. The final comparison group was a Biology II course $(n=28)$ that covered the content in Optical Allusions but did not use the text. Students in each of the four classes completed both the pre- and the postinstruments. In all cases, items with significantly different medians also had significantly different means. Medians for each group have been plotted using box plots (Figure 3).

\section{Content Knowledge}

A significant improvement was observed in the median content knowledge scores for all groups: Sensory Biology $(p<$ $0.0001)$, Organic Evolution $(p=0.0313)$, Neurobiology $(p=$
0.0001), and Biology II ( $p<0.0001)$. The lowest median content knowledge scores were observed within the Sensory Biology course at the preinstruction time point. We believe that this can be attributed to the fact that Sensory Biology is composed of non-science majors taking the course to fulfill distribution requirements.

\section{Biology Attitude Scores}

Attitude scores show a significant improvement in both the median overall BAS and Part A scores for Sensory Biology ( $p$ values 0.0128 and 0.0104 ) and Organic Evolution ( $p$ values 0.0039 and 0.0313 ). The lowest mean and median attitude scale scores were observed within the Sensory Biology course at the preinstruction time point.

Further, in Organic Evolution, those with preinstruction content knowledge score at or below the class median had a significantly higher increase in their BAS Part A score $(p=$ $0.0360)$ and a marginally significant higher increase in their BAS Part B ( $p=0.059)$, on average, than those scoring above the median. As one might expect the increase in attitude toward biology to be nearly constant among all levels of biology students, this significant improvement suggests that the text may help engage those who initially know less content.

Table 3. One-way ANOVA results

\begin{tabular}{lccc}
\hline & & & Results of Dunnett's post hoc test \\
\cline { 3 - 3 } Response & $\begin{array}{c}\text { Overall F test } p \\
\text { value }(3,71 \mathrm{df})\end{array}$ & Course & $\begin{array}{c}\text { Mean increase above } \\
\text { comparison group }\end{array}$ \\
\hline BAS change & 0.0586 & Sensory Biology & $5.89(\mathrm{SE} 2.219)^{\mathrm{a}}$ \\
BAS Part A change & 0.0107 & Sensory Biology & $5.35(\mathrm{SE} 1.646)$ \\
BAS Part B change & 0.9409 & Sensory Biology & 0.0278 \\
CAS change & 0.0436 & Sensory Biology & 6.24 (SE 2.531) \\
CAS Part A change & 0.0661 & & 4.43 (SE 1.767) \\
CAS Part B change & 0.0819 & & 0.0450 \\
Content knowledge & 0.1068 & & 0.0407 \\
\hline
\end{tabular}

${ }^{\text {a }} \mathrm{SE}=$ standard error 

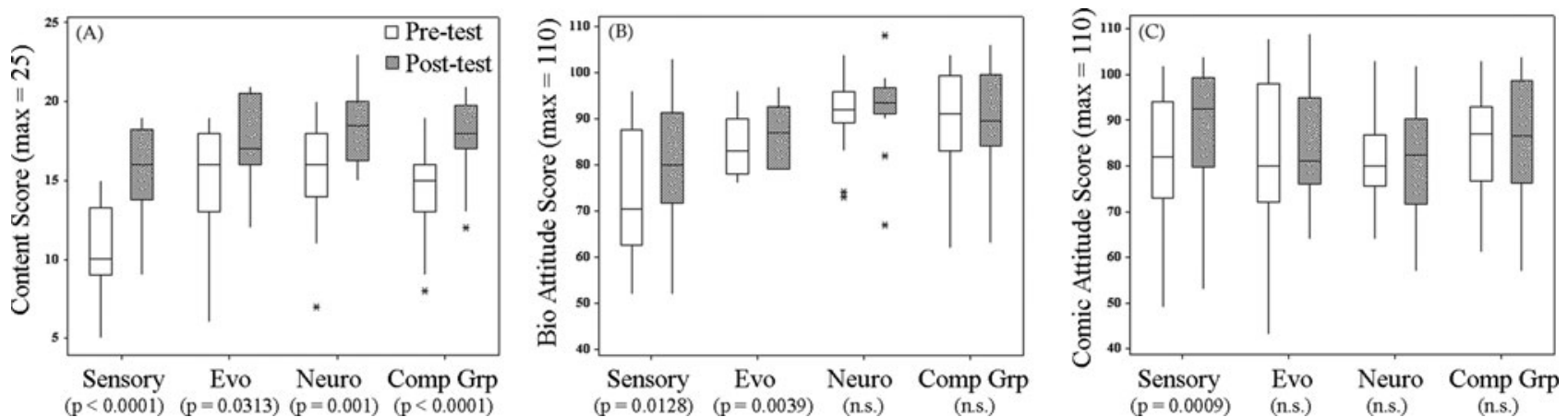

Figure 3. Box plots show range and median of pre- and postinstruction scores by course (outliers denoted with asterisks). (A) Postinstruction median scores on the content assessment are significantly higher than on the pretest for each course. The largest gains in improvement are seen in the Sensory Biology and the Comparison Group (Biology II) course, in which $75 \%$ of the students postinstruction scored above the pretest 75th percentile. (B) Neurobiology students consistently have higher BAS scores than students in the other courses. Sensory Biology students show the largest increase in BAS scores postinstruction, with $75 \%$ of the students scoring above the preinstruction median score. (C) CAS scores are a more variable assessment measure. Significantly increased CAS scores were observed among the Sensory Biology students.

Individual change trajectories are plotted for each student in the Sensory Biology or Organic Evolution course (Figure 4). Observing each student's BAS score at the start and the end of the respective course demonstrates an overall positive change in attitude toward biology for most students. This supports that an increase was reported for a large group of students (as opposed to one to two students driving the significant change). As with any graphical summary, this does not imply that every student did, or will in future studies, show a positive increase in attitudes toward biology. Some students indicated a negative change or no change in attitude score.

No significant improvement was observed in the BAS for Neurobiology (BI 450) or Biology II (BI 106). It is worth noting, however, that the overall BAS score for the Neurobiology course at the start of the semester was higher, on average, than that for the other courses, at either time point. Thus, these students began the course with a strong positive attitude toward biology. Recall that this is a 400-level course and most students have completed more biology courses than those in Organic Evolution.

\section{Comic Book Attitude Scores}

All groups showed comparable CAS scores on the preinstruction instrument. Only Sensory Biology showed a significant increase in the median CAS score (overall, $p=0.0006$; Part A, $p=0.0031$; and Part B, $p=0.0006$ ) after using Optical Allusions.

\section{Analysis of Variance}

One-way ANOVAs were performed to assess whether the mean change in BAS and CAS scores (overall, Part A, and Part B) and in knowledge gain differed among the four courses used in this study (Table 3). Course had a significant effect on the mean change in BAS Part A $(p=0.0107)$ and the overall change in CAS $(p=0.0436)$. The effect of course was approaching significance for the mean overall BAS change $(p=0.0586)$ and the mean CAS Part A change $(p=0.0661)$. In each of these four analyses, the post hoc Dunnett's test found that the mean change for students in the Sensory Biology course was significantly higher than for students in the Biology II course.
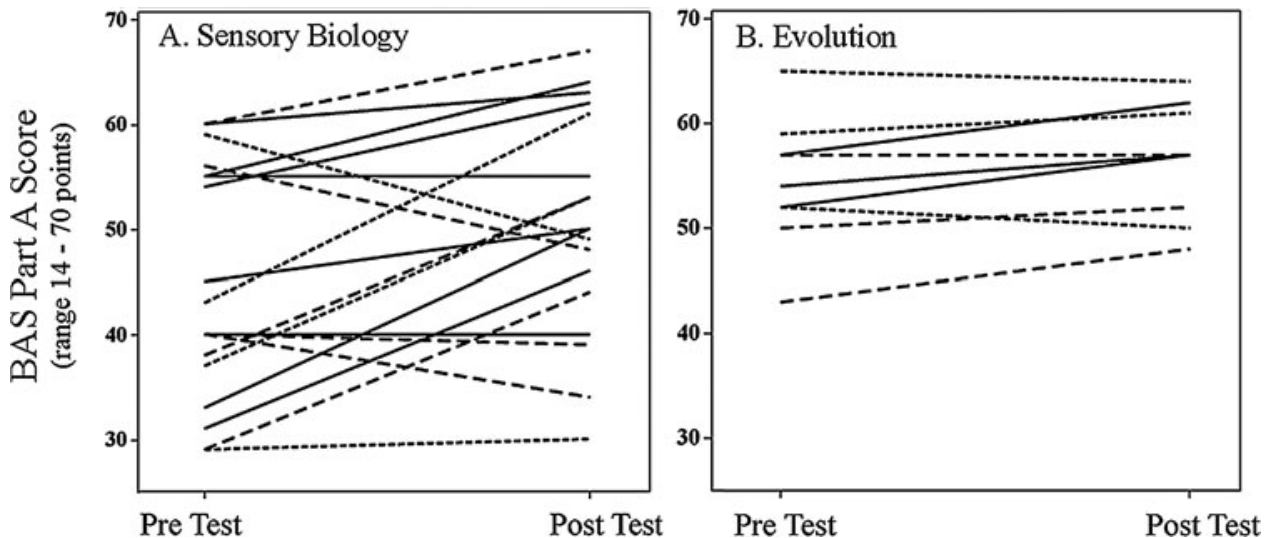

Figure 4. Trajectory plots of changes in individual student scores on the BAS Part A for (A) Sensory Biology and (B) Evolution. The majority of students showed a general improvement in attitudes between the pre- and posttest. Solid lines are students who scored above the median on the content pretest, dashed lines are students who scored below the median on the content pretest, and dotted lines are students who scored at the median on the content pretest. 


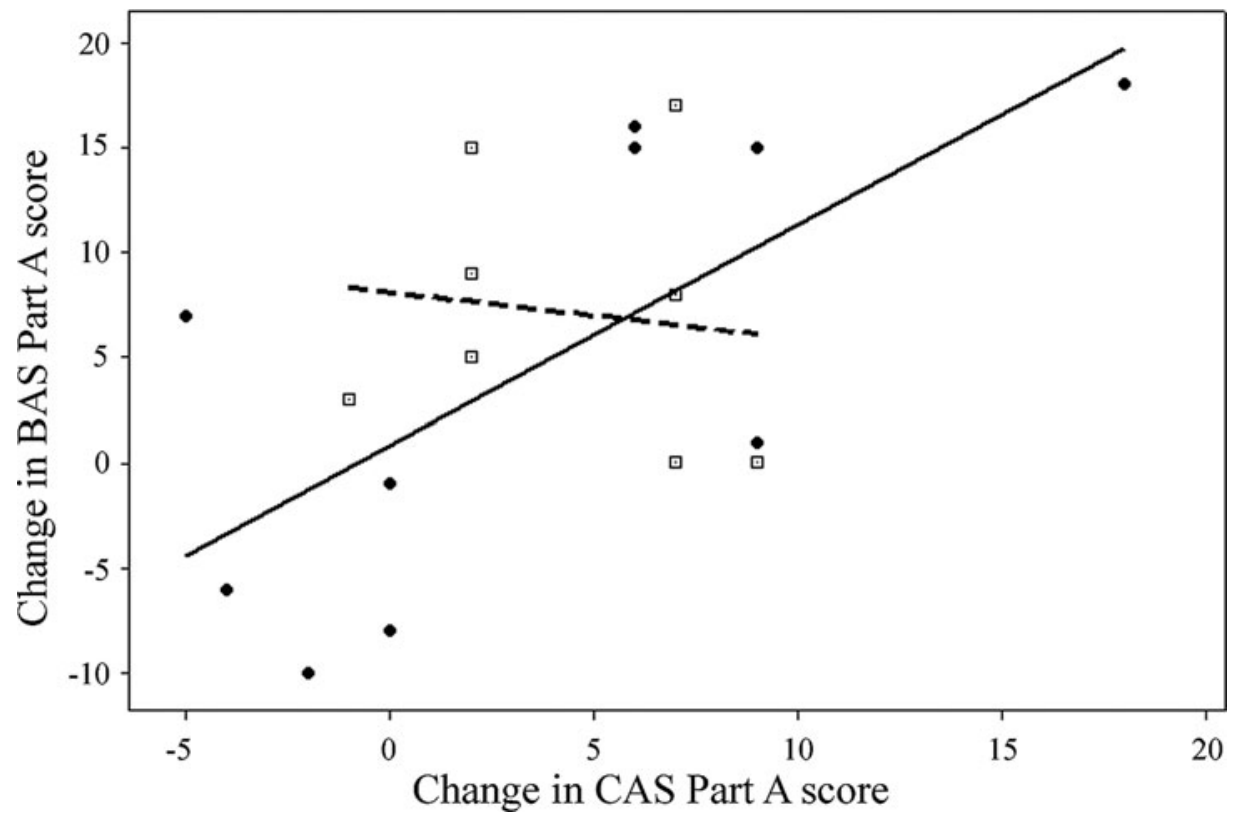

Figure 5. Scatterplot showing the association between the BAS Part A scores and the CAS Part A score for the Sensory Biology class. Two trend lines are shown; those who scored above the class median on the content knowledge pretest show no association between the two scores (dashed line, $p=$ 0.749 ). Students scoring at or below the median on the pretest content knowledge show a positive association (solid line, $p=0.030$ ). Those who initially knew less about biology seem to have a stronger linear association between BAS and CAS Part A scores, on average.

\section{The Association between Attitudes about Biology and Comics}

The median CAS scores (overall, Part A, and Part B) were similar among the three courses at the start of the semester. At the end of the semester, a significant increase in the CAS scores was observed within the Sensory course (with a median increase in the overall CAS score of 6 points). Further, the change in Part A of the BAS score (median 5.78) is positively correlated with a change in Part A of the CAS score (median 4.00; Spearman correlation of $0.496, p=0.036$ ). Students who reported decreasing attitude scores on the CAS tended to also report a decrease in attitude toward biology; students who reported an increase in attitude toward comics tended, on average, to show an increase in attitude toward biology. The association between one's change in Part A of the BAS and one's change in Part A of CAS seems to be related to the student's content knowledge at the start of the semester. Figure 5 illustrates the association between change in attitude toward biology and comics for those who scored above the median on the preinstruction content instrument and for those who scored at or below the median. The association between attitudes toward biology and comics seems to be stronger and more positive for those beginning the course with less content knowledge (Spearman correlation 0.681, $p=0.030$ ); among students beginning the semester with more content knowledge (content pretest scores above the median), no association is observed (Spearman correlation -0.136, $p=0.749)$ These results suggest that a graphic novel approach is positively received among nonmajors who begin the course with lower content knowledge.

\section{DISCUSSION}

Years of pedagogical research and stacks of lavishly illustrated textbooks support the idea that words and pictures work well together for instruction. The visual component of comics is undoubtedly part of their appeal and might provide a mechanism to improve student performance. When text and images are combined, reading performance and retention improves compared with nonillustrated text (Sones, 1944; Gambrell and Jawitz, 1993; Carney and Levin, 2002). In fact, coupling visual information with verbal explanations can lead to more creative problem solving for some students (Mayer and Sims, 1994). Comics have been used to promote student literacy (Gorman, 2003; Tilley, 2008) and have been shown to lead to other reading (Krashen, 1993), and most educators agree that reading is the primary predictor of academic success (Krashen, 1993). In some literature courses, comics seem to help high school students forge a more substantial bond with the characters (Versaci, 2001). Finally, comics tell stories. By scaffolding educational material with stories, comics can make use of situational narratives to provide context for material and thus a mechanism for improving student learning (Dillon, 1981; Caine and Caine, 1991; Wirth and Gamon, 1999).

The question we ask here is whether a comic book's unique blend of words, images, and storytelling can be used to teach and engage students, in general, and among non-science majors in particular. It is important to note that the Sensory Biology class was very different from the other three comparison groups. The majority of students in Sensory Biology were social science majors in their first year of college. In contrast, students in Biology II were primarily sophomore biology majors, whereas those in Organic Evolution and Neurobiology were an even more rarefied group, consisting overwhelmingly of senior biology majors. Given the constituencies, it may not be surprising that the initial content mastery and attitudes about science seen in Sensory Biology are significantly lower than those seen in the other three classes.

The Optical Allusions text was used in one introductory biology course for nonmajors and two courses for majors. A significant increase in the median content knowledge scores was observed in each of the four courses, suggesting that the comic book was as effective at conveying information in the three classes in which it was used as the more traditional 
textbook used in Biology II. Obviously, one might expect an improvement in content knowledge after using any instructional materials. However, in a culture where comics still carry a strong negative stigma, it is important to demonstrate that comics didn't actually cause a decline in student understanding.

Optical Allusions also engaged non-science majors who started the semester with a lower opinion of science than their science major peers. A significant increase in the BAS was observed in the nonmajors Sensory Biology course (median increase of 5.5 points overall and 6 points on Part A) and in Organic Evolution students scoring below the median on the preinstruction content test (median increase of 2 points overall and 4 points on Part A). No such change was seen between the pre- and postinstruction instrument for the Biology II course (an introductory-level biology class) and Neurobiology (a 400-level class composed primarily of seniors), in large part because they were very high at the beginning. The latter results may be indicative of a ceiling effect among these upper-level majors.

The attitude shift in the major's evolution class seems to be due to a shift in the attitudes of students in the lower half of the class. Students who scored less than the median on the preinstruction content test had a significantly greater improvement in Part A of the BAS than students who performed better on the preinstruction content test. This significant increase in attitudes toward biology, in conjunction with a significant increase in content knowledge, suggests a more positive role of the Optical Allusions text among nonmajors and weaker biology majors than among strong biology majors, as no significant change in attitude toward biology was observed in the Neurobiology course.

Of course, one potential concern for our interpretation of these results is the possibility that the significant improvement in BAS was a result of one or two students exhibiting a dramatic attitude shift. If this were the case, such outliers might obscure unchanged attitudes or an overall decline in attitudes of the majority of students. For this reason, we assessed trajectory plots of changes in individual student attitudes. Although there are students in each class whose attitudes toward biology decline after using the book, these trajectory plots indicate generally positive trends by the majority of students. This holds true when we examine the attitudes of students scoring at or below the median on the content test, indicating that the attitude gains in this group are not being driven by one or two students.

These changes in individual student attitudes about biology were positively correlated with changes in their attitudes about comics. As the text-based biology content was presented in comic format, a positive association between one's attitude toward comics and biology may suggest that this comic book could have played a role in influencing student attitudes about biology. Taken all together, our results suggest that, with regard to student learning, comic book stories lose nothing to traditional textbooks while having the added potential benefit of improving attitudes about biology.

Although these results are promising, a number of challenges and new questions need to be addressed. First, while our comparison groups played a valuable role in supporting previously established differences in biology attitudes between non-science majors and science majors (see Knight and Smith, 2010), the attitude changes over time were more visible for the nonmajors than the majors, the latter being rendered less effective possibly by a ceiling effect. Second, future comparative studies will benefit from a well-defined control that receives content instruction without a comic and a treatment group that receives the same instruction supplemented with an appropriate comic. We plan to do this with a more systemic set of in-class and out-of-class experiments. Finally, we must assess whether these results suggest comics in general can be an effective pedagogical tool in the classroom or do they apply only to the book discussed here? Given the general appeal of comics, images, and stories, it seems likely we are talking about comics in general, but testing this with other comics will be an essential next step. (For those interested in pursuing this question in courses in other fields, one of us [J.H.] has started a free web resource at http:/ / comicbooksyllabus.com designed to list comics suitable for use in the natural sciences, social science, and humanities.) Second, we must determine whether nonmajors' attitudes improved because of the comic format or just the fact that it used a situated narrative to provide context for the information. Would embedding content in a prose story be as effective or is there something inherently motivating about comics that engage students? Finally, to test the role of comics in general on student attitudes, future experiments will benefit from more precisely controlled experimental design, specifically creating randomly selected groups that share similar demographics. We are currently outlining experiments to examine these questions.

\section{ACKNOWLEDGMENTS}

The authors thank Mike Boyle and the members of the Juniata College Scholarship of Teaching and Learning group for their comments, criticisms, and insights in designing this study.

This material is based on work supported in part by a Course Curriculum and Laboratory Improvement grant from the National Science Foundation (\#0536737).

Any opinions, findings, and conclusions or recommendations expressed in this material are those of the author(s) and do not necessarily reflect the views of the National Science Foundation.

\section{REFERENCES}

Caine RN, Caine G (1991). Making Connections: Teaching and the Human Brain, Upper Saddle River, NJ: Dale Seymour Publications.

Carney RN, Levin JR (2002). Pictorial illustrations still improve students' learning from text. Educ Psychol 14, 5-26.

Dillon GL (1981). Constructing Texts, Bloomington, IN: Indiana University Press.

Eisner W (1944). "Joe Dope." Army Motors Magazine.

Gambrell LB, Jawitz PB (1993). Mental imagery, text illustrations and children's story comprehension and recall. Reading Res Q 28, 264276.

Gerde VW, Foster RS (2008). X-Men ethics: using comic books to teach business ethics. J Bus Ethics 77, 245-258.

Gorman M (2003). Getting Graphic: Using Graphic Novels to Promote Literacy with Preteens and Teens, Worthington, OH: Linworth Publishing.

Green MJ, Myers KM (2010). Graphic medicine: use of comics in medical education and patient care. Br Med J 340, 574-577.

Grigg WS, Lauko MA, Brockway DM (2006). The Nation's Report Card: Science 2005 (NCES 2006-466). U.S. Department of Education, 
National Center for Education Statistics. Washington, DC: U.S. Government Printing Office.

Haugaard K (1973). Comic books: conduits to culture. Reading Teacher 27, 54-55.

Hutchinson K (1949). An experiment in the use of comics as instructional material. J Educ Sociol 23, 236-245.

Kakalios J (2002). Adding Pow! to your physics class with comic-book lessons. Curriculum Rev, 14-15.

Knight JK, Smith MK (2010). Different but equal? How nonmajors and majors approach and learn genetics. CBE Life Sci Educ 9, 3444.

Krashen S (1993). The Power of Reading: Insights from the Research, Englewood, CO: Libraries Unlimited.

Maryland State Department of Education (2004). MSDE Launches Comic Book Initiative to Boost Reading. MSDE news release: www.marylandpublicschools.org/NR/exeres/ 1B54A4D3 - DF86 - 48D5 - BAE5 - E5BEE05032EB,frameless.htm?Year $=2004 \&$ Month $=12 \% 25 \% 3 \mathrm{E}$ (accessed 9 July 2010).

Mayer RE, Sims VK (1994). For whom is a picture worth a thousand words? Extensions of a dual-coding theory of multimedia learning. J Educ Psychol 86, 389-401.

National Science Board (NSB) (2000). Communicating Science and Technology in the Public Interest (NSB Publication No. NSB-00-99), Arlington, VA: National Science Foundation.
NSB (2004). Science and Engineering Indicators 2004 (NSB Publication No. NSB 04-01), Arlington, VA: Division of Science Resources Statistics, National Science Foundation.

Ottaviani J (2009). Dignifying Science, 3rd ed, Ann Arbor, MI: G.T. Labs.

Rogers WD, Ford R (1997). Factors that affect student attitude toward biology. Bioscene: J Coll Biol Teach 32, 3-5.

Russell J, Hollander S (1975). A Biology Attitude Scale. Am Biol Teacher 37, 270-273.

Sones W (1944). The comics and instructional method. J Educ Sociol $18,232-240$.

Tatalovic M (2009). Science comics as tools for science education and communication: a brief, exploratory study. J Sci Comm 8, A02.

Tilley CL (2008). Reading comics. School Library Media Activities Monthly 24, 23-26.

Versaci R (2001). How comic books can change the way our students see literature: one teacher's perspective. Eng J 91, 61-67.

Williams N (1995). The comic book as course book: why and how. Long Beach, CA: Annual Meeting of the Teachers of English to Speakers of Other Languages (ERIC Document Reproduction Service No. ED 390277)

Wirth DM, Gamon JA (1999). The art of situated narrative: a tool to teach environmental ethics. J Vocat Educ Res 24, 45-61. 